\title{
ENHANCEMENT OF RATE OF HEAT TRANSFER USING VORTEX GENERATORS IN AIR HEATER
}

\author{
Aravind C.Angadi ${ }^{1}$, V.V.Katti ${ }^{2}$ \\ ${ }^{1}$ Assistant Professor, Mechanical Engineering Department, S.G.Balekundri Institute of Technology, Belagavi, India. \\ ${ }^{2}$ Professor, Mechanical Engineering Department, V.D.R.Institute of Technology, Haliyal, India.
}

\begin{abstract}
There are many applications in engineering industry that require heat addition or removal and a wide variety of heat exchange devices are used for different applications. Performance of improving coefficient of heat trsnsfer and pressure drop reducing becomes essential in all applications. Most of thermal devices like high temperature gas turbines, heat exchangers, electronic equipment, convective heat transfer plays an major role in most of the engineering applications. There are many methods to enhance rate of heat transfer. Delta wing vortex generators or promoters of turbulence are often used to calculate the flow field and they can give a worth full effect on the performance of thermal device. Many researchers have been studied extensively the applications of heat transfer which involves internal flow and mixed convection in ducts and non-circular ducts such as, rectangular, square, triangular. To attain higher coefficient of heat transfer, it is necessary that the surface of heat transfer flow is to be made turbulent. However, energy for producing such turbulence has to come from the blower or fan and the maximum turbulence leads to excessive power requirement to make the air flow through the duct. Therefore maximum turbulence must be produced in the region which is very near to surface of heat transfer i.e. in the laminar sub-layer only Excessive friction losses can be avoided by making flow should be not unduly disturbed and it is done by making the height of the roughness element to be small as compared with the dimensions of duct. The roughness element height $(e)$ and pitch $(P)$ are the most important parameters to characterize the roughness shape and arrangement. All these parameters namely, angle of attack ( $\beta)$, relative roughness pitch $(P / e)$, relative roughness height (e/D) are usually specified as dimensionless parameters.
\end{abstract}

Keywords: Heat Transfer Enhancement, Vortex generators, Nusselt Number.

\section{INTRODUCTION}

Now a days for the more comfort of the passenger compact Plate-and-fin type heat exchangers having multilayer fins are using in automotive air conditioning system. Because of best performance of heat exchanger demands are increasing. Specially for the reasons of more compactness of the heat exchanger, economical at costs concerned to manufacturing and operation, conservation of energy point of view and even ecology is taken into account. The importance of above issues makes us to study different techniques to enhance the rate of heat transfer. We studied that convective resistance to heat transfer is maximum at air side that is upto $75 \%$ in a typical refrigerant-to-air heat exchanger, as per Anil Kumara, R.P. Saini, J.S. Saini, 2012[1]. Airside surface are very much preferring for enhancing the rate of heat transfer. As per M.C.Gentry \& A.M.Jacobi, 1997[4].vortex generators which are placed by passive method can enhances the air side heat transfer which is one of the good technique in a wide range of applications.AccordingtoY.Chen,M.Fiebig,N.K.Mitra,2000[ 11]. Stream wise vortices which are created by delta wing vortex generators and heat exchanger carries these vortices. Due to mixing of bulk fluid and main flow boundary layer becomes thinner. Joardar, A.M. Jacobi, 2008[3] implemented with low cost with minimum pressure loss and studied the above enhancement technique.
There are many applications in engineering industry that require heat addition or removal and a wide variety of heat exchange devices are used in these applications. Performance improvement means improving coefficient of heat transfer and minimizing the pressure loss as per Qiuwang Wang,Qiuyang Chena, Ling Wang, Min Zenga, Yanping Huangc, Zejun Xiaomay, 2006[6]. becomes essential. Most of thermal devices like high temperature gas turbines, heat exchangers, electronic equipment, convective heat transfer plays an major role. There are many methods to enhance heat transfer. Delta wing vortex generators or promoters of turbulence are often used to calculate the flow field and they can give a worth full effect on the performance of thermal device. Many researchers have studied applications of heat transfer involving mixed air flow and internal flow in non circular ducts such as rectangular ,square ducts etc as per S.W.Ahn,2001[7]. Rectangular ducts are selected in order to cool vanes and turbine blades effectively and also to have more compactness. There are large number of methods for increasing heat transfer coefficients, which are namely active, passive, or compound. These active methods needs external source, such as mechanical devices, fields of electric, acoustic or any vibration of surface, whereas passive methods do not need outside source, but for this special geometry of surface is the primary requirement. Enhancements that simultaneously uses more than one method are called as compound methods. I have discussed only passive techniques in this paper. Two strategies on 
which the passive method of heat transfer enhancement strongly depends are; mixing of bulk fluid and making disturbance to the layer of thermal boundary. In the presence of roughness elements as per J.L.Bhagoria, J.S.Saini, S.C.Solanki 2002 [2]. Disturbing and boundary layer restarting results heat transfer increase by making on as average thinner boundary layer than boundary layer which is not disturbed by roughness elements. Heat transfer rate can be enhanced through mixing of the bulk fluid by creating vortices in the flow. as per Ya-Ling, Wen-Quan Tao, Yu-Wen Zhang, TaoXie,2012[12]. which minimizes temperature difference in the core flow and concentrates near to wall region thus temperature difference is increased . Using vortex generators, ribs, dimples Such fluid mixing can be observed. The heat transfer enhancement method that makes use of vortex generators is known as vortex-induced enhancement technique. The experimental results for inline arrangement of delta wings as per M.S.Aris, Owen, C.J.Sutcliffe, 2011[5]. for limited configurations are presented here. The influence of geometrical parameters of delta wings such as pitch to vortex generator height ratio as per Teerapat Chompookham, Chinaruk Thianpong,Pongjet Promvonge, 2009[10]. height to hydraulic diameter ratio, aspect ratio as per Sukhmeet Singh, Subhash Chander 2012[9]. of vortex generators, and Reynolds number as per Santosh B. Bopche, Madhukar S.Tandale, 2009[8]. on the enhancement of heat transfer is discussed.

The character of Heat exchangers having square paths are i) The ratio of heat transfer area to core volume is high. ii) shell and tube heat exchangers are having more fabrication costs than this. that iii) It can be constructed with the help of very thin materials and with even very thin foils, its mechanical strength is comparatively high. From the literature survey we found that rectangular ducts have best rate of heat transfer performance than, semi-circular ,circular ducts. Therefore in my experiment, I have used rectangular duct for the study.

\section{EXPERIMENTAL DETAILS}

The experiment has been carry out to investigate heat transfer characteristics for flow through rectangular channel in solar air heater at different Reynolds numbers with a systematic variation of the various geometrical parameters of delta wing type vortex generators. The study is basically intended to find out the effect of different height of vortex generator tip from the plate surface of the rectangular duct on the $\left(N u_{o} / N u_{s}\right)$ ratio of Nusselt number for air flow in the rectangular duct, to study the effect of different pitches that is distance between the two wings in the channel on $\left(N u_{o} / N u_{s}\right)$ ratio of Nusselt numbet and to evaluate how the ratio of Nusselt $\left(N u_{o} / N u_{s}\right)$ number changes as happens change in aspect ratios of the wings for different Reynolds numbers.

Delta wing vortex generators are placed upon the rectangular duct surface to analyze the flow characteristics. The sides of the ducts are noted by W, $L$ and $H$ and channel aspect ratio $(A R)$ is $W / H$.

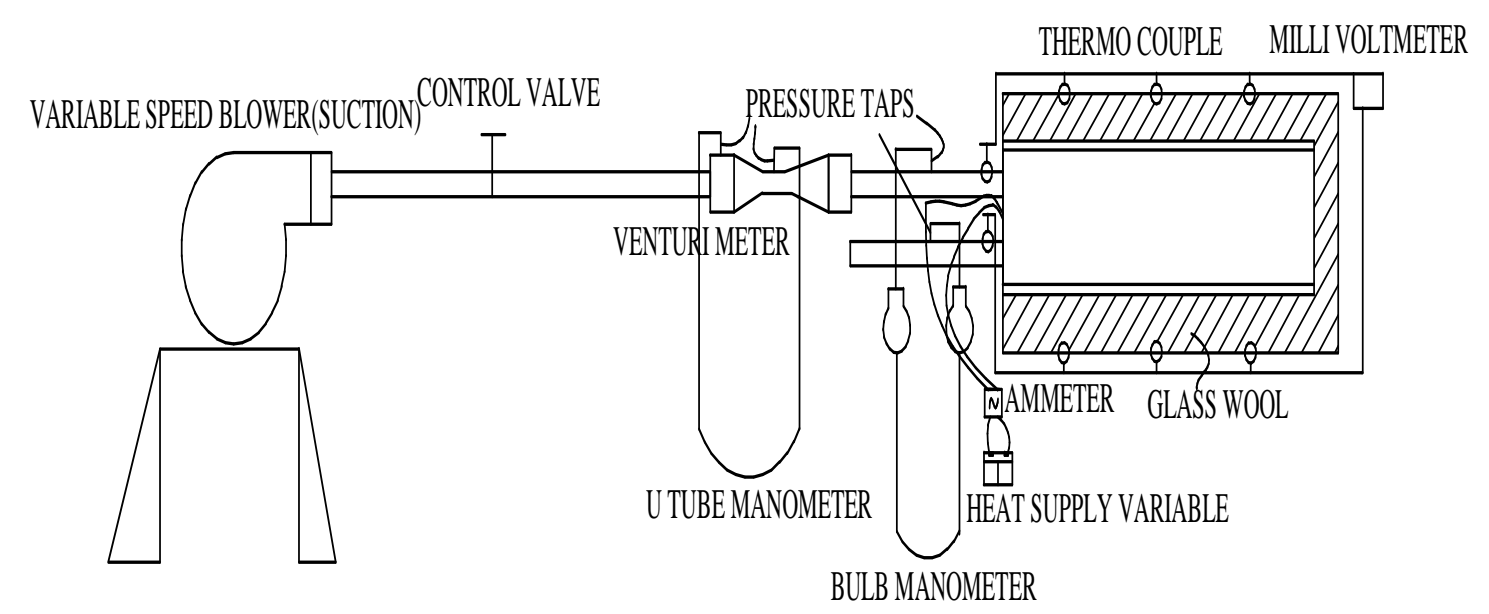

Fig-1:Experimental set-up

The experimental set up diagram of solar air heater is above in the Fig. 1 Inside test section Copper plate having size of $320 \mathrm{~mm} * 53 \mathrm{~mm}$ fine smooth surface is machined and drilled with $2 \mathrm{~mm}$ diameter, $10 \mathrm{~mm}$ deep three holes on either side of the copper plate for fixing the thermocouples. Totally eight thermocouples are used in which six thermocouples are used to note down plate surface temperature at different span and remaining two are for measuring inlet and outlet temperatures. Inside the thermocouples there will be two wires and one of the wires is attached to cold junction and other is cut at the middle. These cut parts are connected to milli voltmeter and selector switch. Selector switch is used to connect all these thermocouples and to note down eight thermocouples temperatures which are displayed on the milli voltmeter. These milli voltmeter readings can be converted into temperatures using the expression

$$
T=(24.52 * \text { milli voltmeter readings }+3.986) .[1]
$$

Three Aluminum strips having dimensions $(1 \mathrm{mmx} 10 \mathrm{mmx} 300 \mathrm{~mm})$ are fixed on heater plate like two way pass heat exchanger to make four rectangular channels with $13.25 \mathrm{~mm} \times 320 \mathrm{~mm}$ dimensions. Heater is made by using Mica sheet to match with dimensions of Copper plate 
(Heater plate) in order to heat the Copper plate. Heater has two coils; one is connected to dimmer stat and other to ammeter. Dimmer stat is used to give variable supply to the test section and corresponding current can be noted from ammeter. Glass wool is filled in the box of test section for insulation purposes to avoid heat loss. Wood box of test section having (inner dimensions: $133 \mathrm{~mm}$ width, $102 \mathrm{~mm}$ depth and $320 \mathrm{~mm}$ length and $10 \mathrm{~mm}$ thickness) is constructed. Bakelite sheet is cut and used (6 holes) on either side of Copper plate to avoid shock and also used (133mm width, $10 \mathrm{~mm}$ depth and $320 \mathrm{~mm}$ length) nearly touching top side of the strips as separator at the center.
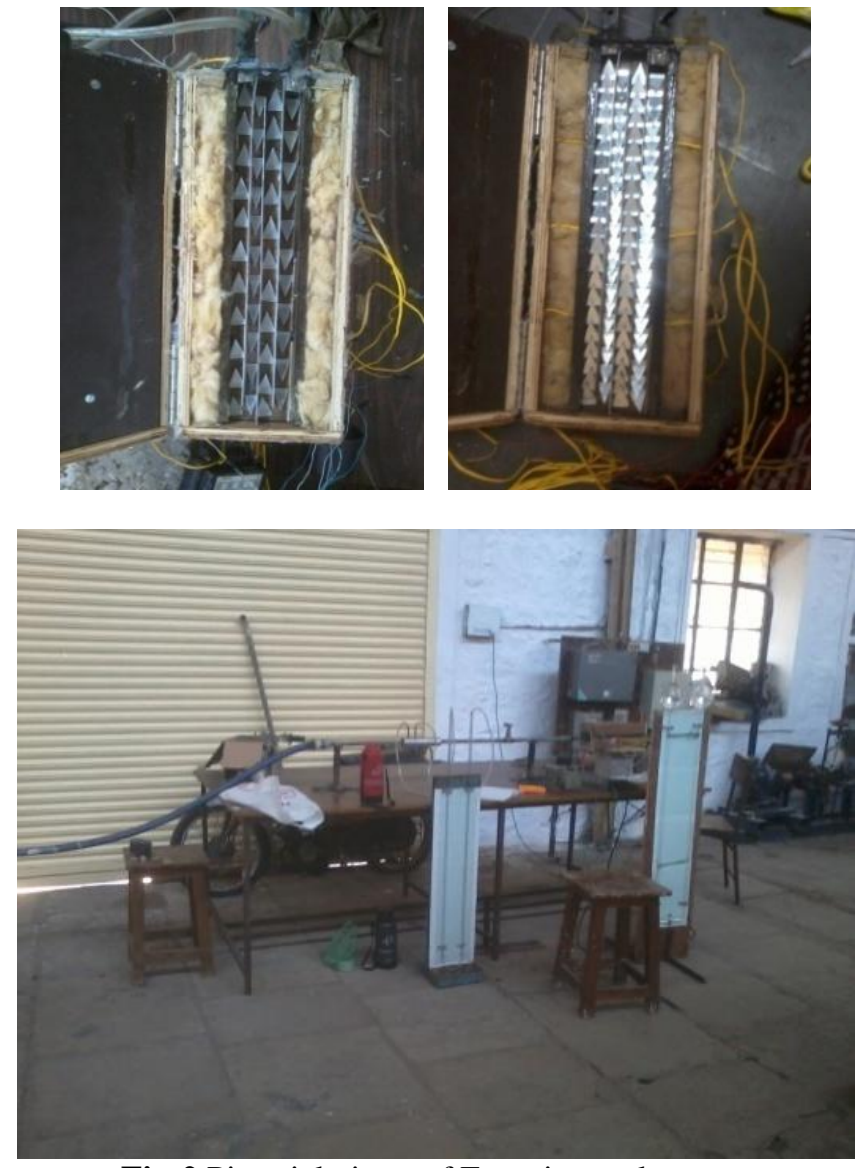

Fig-2.Pictorial views of Experimental set up.

\section{TERMINOLOGY}

pitch $(p)$ : the axial distance between the identical points of adjacent vortex generators is the pitch of the vortex generator configuration.

Vortex generator height $(\boldsymbol{e})$ : vortex generator tip and the surface of the wall upon which it is glued distance is the vortex generator height.

Vortex generator base $(\boldsymbol{b})$ : the span wise dimension of the vortex generator at which it is glued to the wall surface is the base or span of vortex generator.

Chord length (c): the distance of the vortex generator tip from its base measured along the surface of the vortex generator is the chord length of the vortex generator.
Vortex generator height to channel hydraulic diameter ratio $(\boldsymbol{e} / \boldsymbol{D h})$ : this is the ratio of the height of vortex generator tip, measured above the surface upon which they are glued, to the channel hydraulic diameter.

Pitch to height ratio (p/e): It is the ratio of the axial distance between two identical points of the adjacent vortex generators to the vortex generator height.

Aspect ratio ( $a r$ ): the non-dimensional parameter, which is a measure of the shape and size. The aspect ratio for delta wing type vortex generator is given by $a r=2 b / A V G$ or $2 b / c$

Angle of attack $(\boldsymbol{\beta})$ : the angle subtended by the surface of delta wing vortex generator with the surface to which it is glued

Roughened wall width of the channel to the vortex generator base ratio $(N)$ : this is the ratio of the width of the surface upon which vortex generators are glued to the base width of the vortex generator. Since, this value exactly equals the number of span wise rows of the vortex generators it is an integer.

Friction factor: the dimensionless friction factor is defined as $f f_{o} / f f_{s}$ where $f f_{\mathrm{o}}$ is friction factor of square duct with vortex generator and $f f_{s}$ is friction factor of square duct without vortex generator or smooth duct.

Reynolds number: $\operatorname{Re}=\rho v D_{h} / \mu$ where $\mathrm{v}$ is velocity of air in duct, dh is hydraulic diameter, $\rho$ is density of air and $\mu$ is Dynamic viscosity of air.

3.1 Effect of pitch to height ratio ( $p / e)$ on heat transfer (nu) for given reynolds numbers and for different vortex generator height to channel hydraulic diameter ratio $(e / d h)$ :

Fig-3. to Fig-5. shows the effect of pitch to height ratio on heat transfer $(\mathrm{Nu})$ for different Reynolds number with wings having aspect ratios $a r=1.6$ and $e / D h=(0.3,0.45,0.6)$ at constant temperature of $25^{\circ} \mathrm{c}$ in a rectangular duct.Heat transfer rate is indicated by Nusselt number.

For the same plate length, the Nusselt numbers are increasing as longitudinal pitch $(p / e)$ of obstacles getting decreases from (12 to 4 ) for all given Reynolds number and height of obstacles $(e / D h)$ because there are more numbers of rows of obstructions .Due to more number of obstructions, more turbulence is resulted that will cause for the higher coefficient of heat transfer, at the same time the friction factor also getting increases due to increase in the blockage of air flow passage. As per my experimental result for all case,both heat transfer rate and friction factor rate is very high for $p / e=4$ compared to that for $p / e=8$ and for $p / e=12$.In fig 4. Nusselt numbers are going to increase with increasing Reynolds number. For the same $e / D h=0.3$ and ar $=1.6$ for $p / e=4$ configuration Nusselt number is high. Increasing pitch to height ratio $p / e=8$ and for $p / e=12$ Nusselt number decreased as compared to $p / e=4$, because of less number of obstacles created less turbulence that will decreased Nusselt number. 
In Fig-3. results are compared and we investigated that rate of heat transfer for $(p / e=4)$ is $114 \%$ higher than $p / e=8$ and $130 \%$ higher than $p / e=12$ and $162 \%$ higher than smooth duct for same Reynolds number and $e / D h=0.3, a r=1.6$. The trend is followed in Fig-4. and Fig-5. with $e / D h=0.45$ and $\mathrm{e} / \mathrm{Dh}=0.60, a r=1.6$ at temperature of $25^{\circ} \mathrm{c}$.

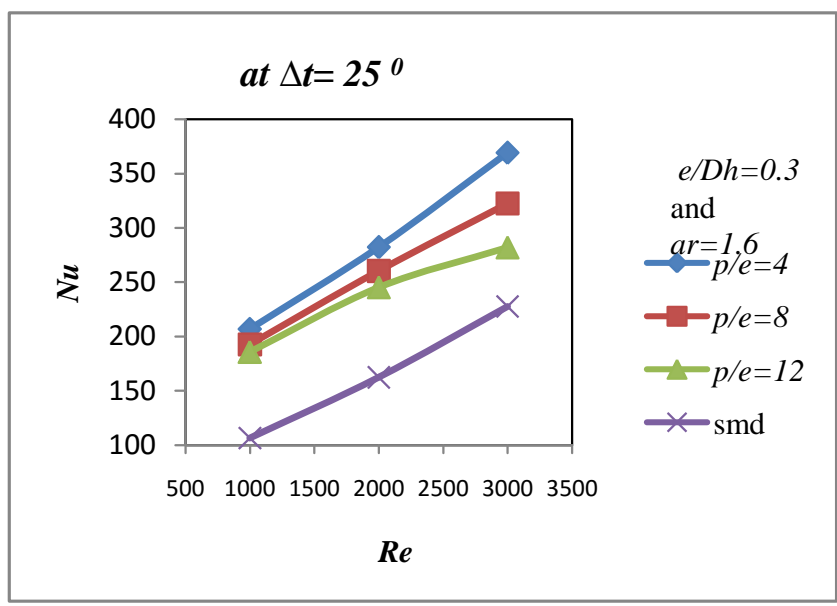

Fig-3. Change of Nusselt numbers for the given Reynolds number and for all different values of $\mathrm{p} / e$

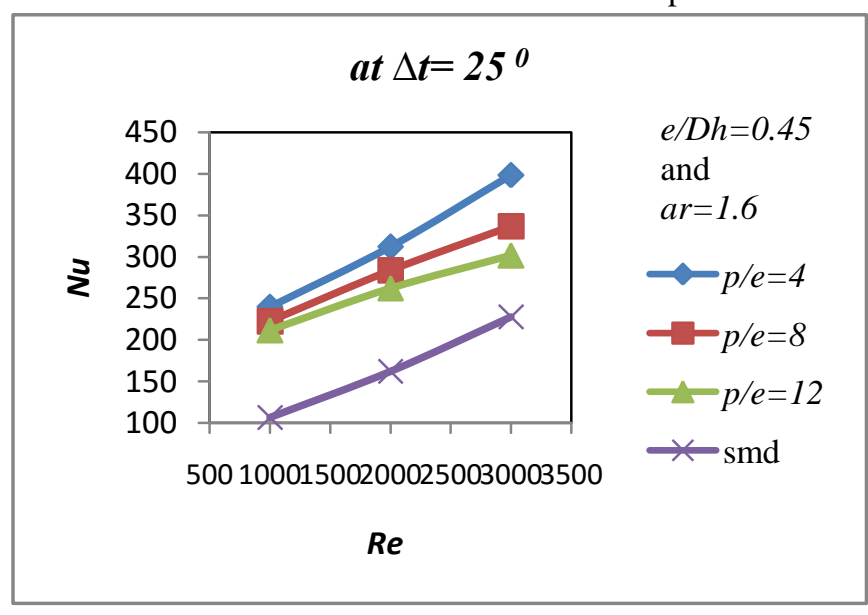

Fig-4. Change of Nusselt numbers for the given Reynolds number and for all different values of $\mathrm{p} / e$

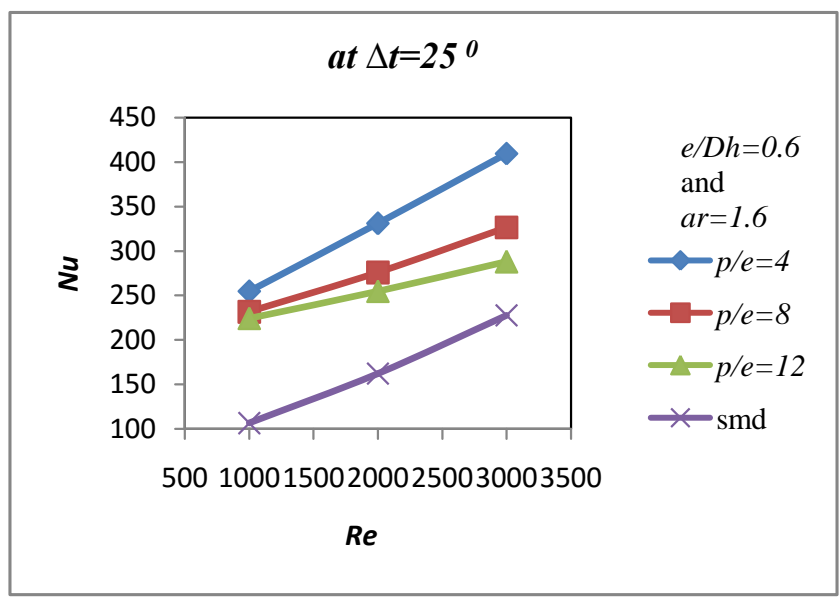

Fig-5. Change of Nusselt numbers for the given Reynolds number and for all different values of $\mathrm{p} / e$
3.2 Effect of vortex generator height to channel hydraulic diameter ratio (e/dh) on heat transfer ( $\mathrm{nu}$ ) for given reynolds numbers and for different pitch to height ratio $(p / e)$ :

Fig-6. to Fig-8. shows the variation of Vortex generator height to duct hydraulic diameter ratio (e/Dh) on heat transfer $(\mathrm{Nu})$ for different Reynolds number with wings having aspect ratios $a r=1.6$ and $p / e=(4,8,12)$ in a rectangular duct. Nusselt number indicates heat transfer rate. For all relative obstacles longitudinal pitch $(p / e)$ and for all given Reynolds number, we observed that there will be increase in Nusselt number as obstacles height $(e / D h)$ increase from 0.3 to 0.6 . This is because as obstacles height increases, the air flow blockage increases and causes higher turbulence that is resulted in higher coefficient of heat transfer. The vortex generator height is directly proportional to angle of attack of the vortex generators in the flow .The angle of attack of vortex generators is increased at higher $e / D h$, core size of vortex and vortex strength is increased. For a given $p / e$, increasing $e / D h$ ratio for the same ' $a r$ ' has the effect of increasing circulation strength and core size of the vortex thereby creating more turbulence to the flow that results into a higher Nusselt number in other words higher heat transfer.

In Fig-6. results are compared and we observed that $t$ rate of heat transfer for $(e / D h=0.6)$ is $102 \%$ higher than $e / D h=0.45$ and $111 \%$ higher than $e / D h=0.3$ and $180 \%$ higher than smooth duct for same Reynolds number and $p / e=4$, ar=1.6. Fig-7.and Fig-8. shows the similar trend as discussed for the $p / e=4$ and $a r=1.6$ case. The increase in $N u$ with increasing Reynolds number and increasing in $\mathrm{Nu}$ with increasing $e / \mathrm{Dh}$ ratio at temperature of $25^{\circ} \mathrm{c}$.

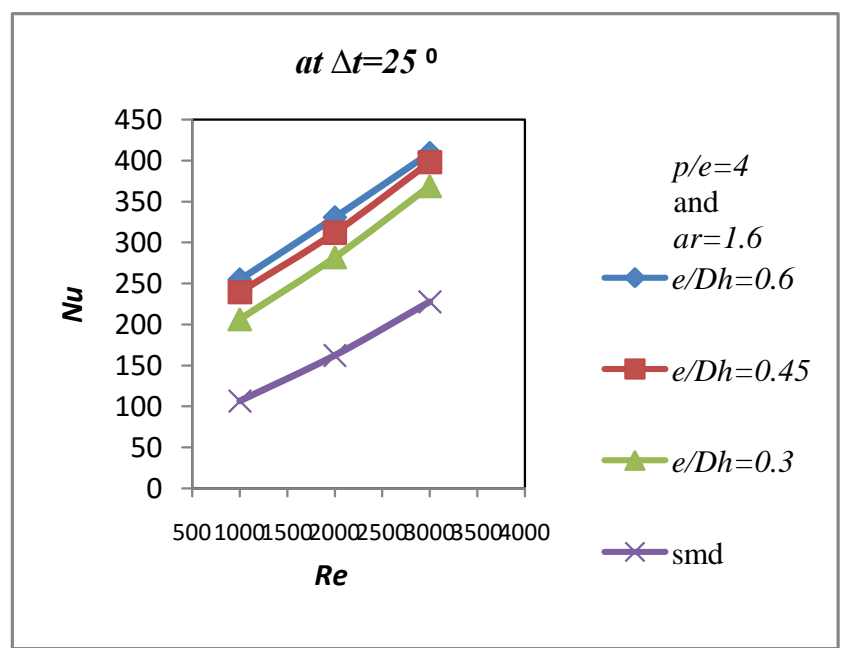

Fig-6. Change of Nusselt numbers for the given Reynolds number and for all different values of $e / D h$ 


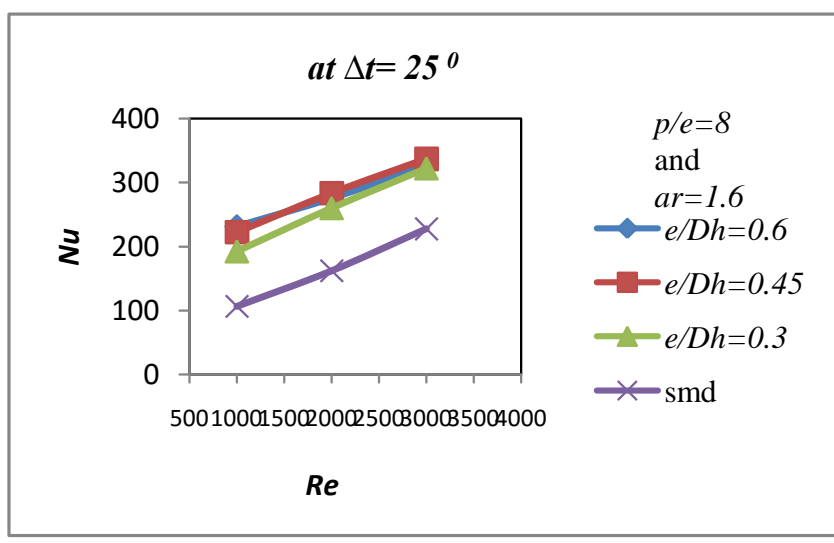

Fig-7. Change of Nusselt numbers for the given Reynolds number and for all different values of $e / D h$

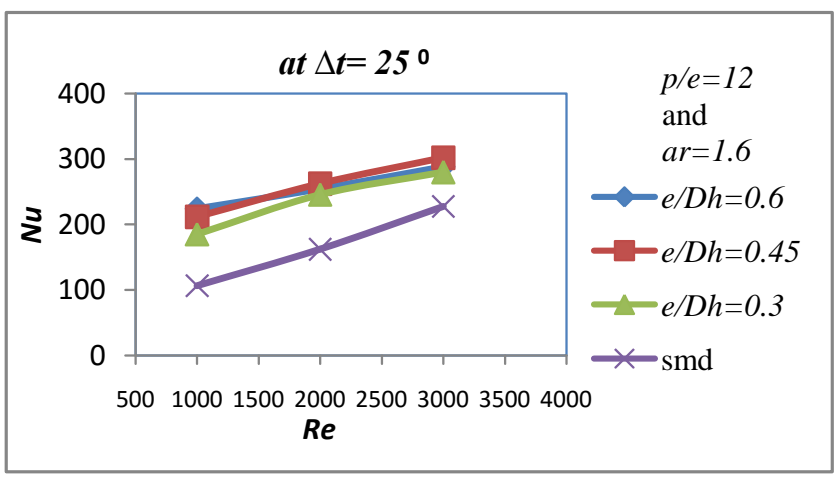

Fig-8. Change of Nusselt numbers for the given Reynolds number and for all different values of $e / D h$

\subsection{Enhancement ratio( $\left.N u_{o} / N u_{s}\right)$ as a function of reynolds number.}

As per my experimental results I have represent the enhancement ratio in the below Fig-9. For $e / D h=0.45$ and $e / D h=0.6$ we observed initially increase in the heat transfer enhancement parameter with Reynolds number and with further increase in Reynolds number there will be slightly decrease in enhancement ratio. But for $e / D h=0.3$ we observed reverse behavior. This is due to higher back flow in the upstream of the obstacles with large increase in Reynolds number that makes the air to flow away from the heated surface near the vortex generators, that causes a long length of reattachment in the downstream flow of generators that can reduce the area of heat transfer of the the heated plate. We observed that as go on decreasing obstacle height, $e / D h$ to 0.3 there will be increased in heat transfer with increasing Reynolds number: However, value wise is lower than which is obtained for obstacle height of 0.45 and 0.6. From the below fig- 9 we observed maximum heat transfer enhancement for $p / e=4$ and $e / D h=0.6$ for the given Reynolds number range.

The heat transfer enhancement for relative obstacles height $(e / D h)$ and longitudinal pitch $(p / e=12)$ is very small amount that is negligible at higher Reynolds number. However there will be increase in heat transfer enhancement with an increase in relative obstacles height for $p / e=8$ and $p / e=4$.

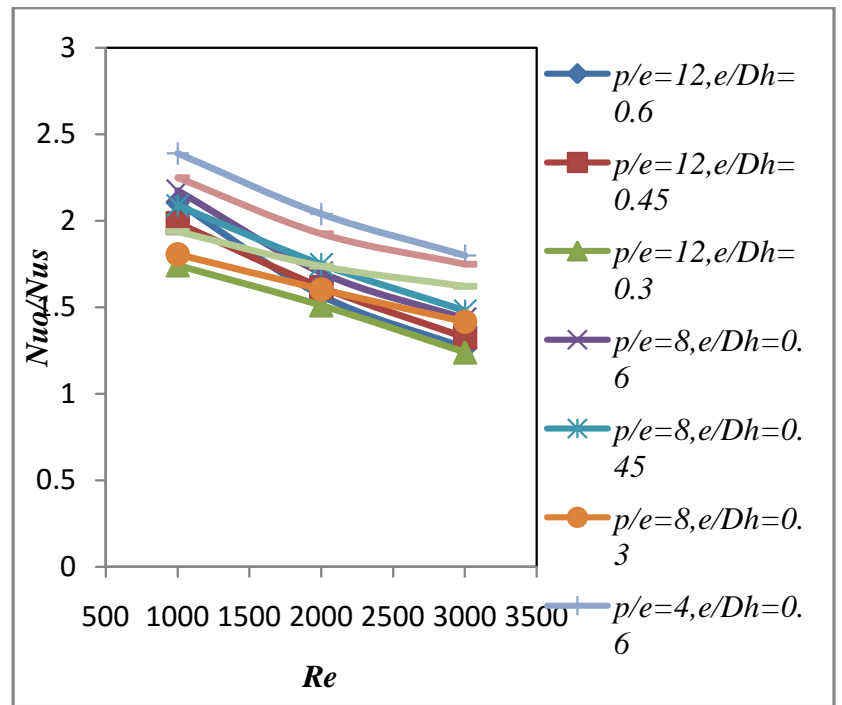

Fig-9: Change of enhancement $\operatorname{ratio}\left(N u_{0} / N u_{s}\right)$, with the given Reynolds number

\section{CONCLUSION}

We conducted the experiment for a given range of Reynolds number $(R e=1000-3000)$ and these results have compared with smooth duct for same flow condition to find rate of heat transfer enhancement and its coefficient. As per the experimental results obtained,it can be concluded as follows.

1. Heat transfer performances of delta wing vortex generators have been found best as compared to smooth duct for the same flow condition.

2. The performance of the duct and flow pattern is greatly affected by Obstacle longitudinal pitch. An enhancement of heat transfer shows by the appropriate obstacle geometry we choose.

3. The Enhancement of heat transfer for all the relative height and any arrangement of obstacles is because of increased turbulence and also because of the secondary air flow producing along the obstacles. Which results in flow of the heated air away from the surface of the plate.

4. As per the experimental results obtained, there is increase in Nusselt number for rectangular duct as compared to smooth duct at Reynolds number $R e=1000$ for given $p / e=4, e / D h=0.6$ and it is of the order of 2.38 .

5. The thermo hydraulic performance obtained is maximum for $p / e=12, e / D h=0.3$ at $\mathrm{Re}=1000$.

\section{REFERENCES}

[1].Anil Kumar, R.P. Saini, J.S. Saini, "Heat and fluid flow characteristics of roughened solar air heater ducts", Renewable Energy, 47 (2012) 77-94

[2]. J.L.Bhagoria,J.S.Saini\&S.C.Solanki, "Heat Transfer coefficient and friction factor correlations for rectangular air heater duct having transverse wedge shaped rib roughness on the absorber plate", Renewable energy, vol 25,pp 341-369,2002

[3]. Joardar, A.M. Jacobi. "Heat transfer enhancement by winglet-type vortex generator arrays in compact plain-fin- 
and-tube heat exchangers" International Journal of

Refrigeration, 31 (2008)8 7 - 97.

[4] M.C.Gentry, A.M.Jacobi, "Heat Transfer Enhancement by Delta-Wing Vortex Generators on a Flat Plate: Vortex Interactions with the Boundary Layer", Experimental Thermal and Fluid Science, 04/1997; 14(3):231-242.

[5]. M.S. Aris a, I. Owen b, C.J. Sutcliffe, "The development of active vortex generators from shape memory alloys for the convective cooling of heated surfaces" International Journal of Heat and Mass Transfer, 54 (2011) 3566-3574.

[6]. Qiuwang Wang a, Qiuyang Chena, Ling Wang a,b, Min Zenga, Yanping Huangc,Zejun Xiao c, "Experimental study of heat transfer enhancement in narrow rectangular channel with longitudinal vortex generators", Nuclear Engineering and Design, 237 (2007) 686-693.

[7]. S. W. Ahn, "The effect of roughness types on friction factors and heat transfer in roughened rectangular duct", Heat Mass Transfer, vol. 28, No. 7, pp. 933-942, 2001.

[8]. Santosh B. Bopche , Madhukar S. Tandale, "Experimental investigations on heat transfer and frictional characteristics of a turbulator roughened solar air heater duct", International Journal of Heat and Mass Transfer, 52 (2009) 2834-2848

[9]. Sukhmeet Singh a, Subhash Chander a, J.S. Saini , "Investigations on thermo-hydraulic performance due to flow-attack-angle in V-down rib with gap in a rectangular duct of solar air heater", Applied Energy, 97 (2012) 907912

[10].Teerapat Chompookham, Chinaruk Thianpong, Sutapat Kwankaomeng, Pongjet Promvonge. "Heat transfer augmentation in a wedge-ribbed channel using winglet vortexgenerators", International Communications in Heat and Mass Transfer, 37 (2010) 163-169

[11]. Y. Chen, M. Fiebig, N.K. Mitra, "Heat transfer enhancement of finned oval tubes with

staggered punched longitudinal vortex generators",

International Journal of Heat and Mass Transfer, 43 (2000) 417-435.

[12]. Ya-Ling He a,Pan Chu a, Wen-Quan Tao a, Yu-Wen Zhang a,b, Tao Xie, "Analysis of heat transfer and pressure drop for fin-and-tube heat exchangers with rectangular winglet-type vortex generators", Applied Thermal Engineering, (2012) 1-14

\section{BIOGRAPHIES}

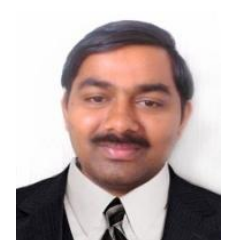

Aravind Angadi completed B.E in mechanical engineering and M.Tech in Thermal power engineering. I am having 2 years of teaching and one year industrial experience. Presently I am working as a Assistant professor in Mechanical Engineering Department in S.G.Balekundri Institute of Technology. 